\author{
Samuel Fernández
}

Facultad de Teología

Pontificia Universidad Católica de Chile

\title{
Circunstancias de la fundación del Hogar de Cristo. Estudio histórico en los documentos contemporáneos (1)
}

Las presentes páginas pretenden identificar, relacionar e iluminar mutuamente los datos contenidos en las fuentes primarias, en especial los manuscritos de San Alberto Hurtado y la prensa contemporánea, que permiten comprender las circunstancias específicas de la fundación del Hogar de Cristo, una de sus obras emblemáticas que ha marcado el alma de nuestro país.

Este trabajo se ha podido realizar con frutos, gracias a los avances realizados en la recopilación, estudio y contextualización de las fuentes primarias para el estudio científico de los escritos y de la vida del santo. Estas fuentes están constituidas por los escritos de San Alberto, es decir, sus publicaciones y manuscritos, y por otras fuentes primarias tales como actas de diversas agrupaciones y, sobre todo, las abundantes noticias sobre Alberto Hurtado que ofrece la prensa contemporánea (2). A estas fuentes primarias, se suma un buen número de estudios serios por parte de diversos especialistas (3). A estos antecedentes, es necesario agregar algunas publi-

(1) Estas páginas ofrecen parte de los resultados del proyecto Fondecyt 1060409 (2006/2007).

(2) Una presentación más detallada del estado del archivo se encuentra en S. Fernández Eyzaguirre, Base documental para el estudio de San Alberto Hurtado. Estado de la cuestión, en Anuario de Historia de la Iglesia (Navarra), XVII (2008), pp. 313-320.

(3) J. Castellón, Padre Alberto Hurtado S.J. Su espiritualidad, Santiago, 1998; T. Mifsud, El sentido social: el legado ético del Padre Hurtado, Santiago, 2005; E. Sánchez et alii, Padre Alberto Hurtado, S.J. La riqueza de su pensamiento, Santiago, 2005; A. Hurtado Cruchaga, Obras jurídicas completas. Con estudio preliminar de Pedro Irureta Uriarte, Santiago, 2005; M. Clavero, Un punto de inflexión en la vida del padre Alberto Hurtado: Itinerario y balance de su viaje a Europa, de 1947, Teología y Vida, 46 (2005), pp. 291-320; J. Ochagavía, Santidad y Teología. Reflexiones en la canonización del padre Hurtado, Teología y Vida, 46 (2005), pp. 427-438; J. Costadoat, Pietas et eruditio en Alberto Hurtado, S.J., Teología y Vida, 46 (2005), pp. 321-352; S. Fernández, 'Ya no vivo yo, es Cristo que vive en mí' (Gál 2, 20): 'Ser Cristo' como clave de la vida del padre Alberto Hurtado, Teología y Vida, 46 (2005), pp. 352-373; P. Espinosa, ¿Es Chile un país católico? Polémica en torno a un libro del padre Hurtado, Teología y Vida XLVI (2005), pp. 625-674; S. Fernández, Relación del Padre Alberto Hurtado, S.J., con la Facultad de Teología de la Pontificia Universidad Católica de Chile, Teología y Vida, 44 (2003), pp. 3-18; S. Fernández, ¿Reformar al individuo o reformar la sociedad? Un punto central en el desarrollo cronológico del pensamiento social de San Alberto Hurtado, Teología y Vida, 49 (2008), pp. 515 544. De gran valor son los números especiales de la revista Mensaje publicados para la beatificación (1994) y la canonización del Padre Hurtado (2005), asimismo el número especial de la revista Humanitas de julio-septiembre de 2005. 
caciones que estudian el contexto histórico de estos acontecimientos, en particular el desarrollo del catolicismo social, en el que se enmarca la obra del Padre Alberto Hurtado (4).

\section{“UN HOGAR PARA LOS QUE NO TIENEN TECHO”}

El 22 de octubre de 1944, El Padre Hurtado publicó en El Mercurio y en El Imparcial la misma columna en que llamaba a realizar una obra "para los que no tienen techo" (5). Este documento, con razón, es considerado el punto de referencia inicial para conocer las circunstancias de la fundación del Hogar de Cristo. En esta breve columna, Alberto Hurtado recuerda que en Chile, por esos años, faltaban 40.000 viviendas, destaca la precariedad de muchas viviendas y describe, con mucha fuerza, la situación de aquellos que viven en la calle, que carecen de una casa. Luego recuerda dos casos muy significativos: el primero, poco conocido, el de "una pobre mujer recogida en una casa caritativa cuando caía víctima de inanición" y otro, mejor conocido, el de "un pobre hombre con una amigdalitis aguda tiritando en mangas de camisa, que no tenía donde guarecerse”. Luego se lamenta que la Iglesia Católica no cuente con un lugar donde enviar a las personas que se encuentran en esta situación, pues solo está el hogar del Ejército de Salvación, y continúa:

“Al predicar unos ejercicios esta semana el pensamiento me ha golpeado más fuerte en forma imprevista: ¿No será el momento de que realicemos este ideal de nuestra fe: dar albergue al mendigo? Apenas propuesta la idea, varias personas la acogieron con gran entusiasmo: también ellas habían sentido la misma atormentadora inquietud: solo faltaba hacerla cristalizar" (6).

Los datos aportados por este breve texto, iluminados por las noticias de prensa, actas, cartas recibidas y manuscritos de Alberto Hurtado, permitirán reconstruir de modo bien preciso las circunstancias específicas de la fundación del Hogar de Cristo.

\section{ANTECEDENTES: PREOCUPACIÓN POR LOS SIN CASA}

Un par de notas acerca de la vagancia infantil del El Diario Ilustrado, del año 1944, permiten hacerse una idea de la preocupación de la sociedad por la falta de

(4) M.A. Huerta Malbran, Catolicismo social en Chile: pensamiento y praxis de los movimientos apostólicos, Santiago, Ediciones Paulinas, 1991; P. Valdivieso Fernández, "Cuestión social” y doctrina social de la Iglesia en Chile (1880-1920): ensayo histórico sobre el estado de la investigación, en Historia, vol. 32 (1999), pp. 553-573; Idem, Dignidad humana y justicia: la historia de Chile, la política social y el cristianismo (1880-1920), Santiago, Eds. Universidad Católica de Chile, 2006; J. Gómez Ugarte, Ese cuarto de siglo...: veinticinco años de vida universitaria en la A.N.E.C. 1915-1941, Santiago, Andrés Bello, 1985; R. Sagredo - C. Gazmuri, Historia de la vida privada en Chile, Vol. III (desde 1925 a nuestros días), Santiago, Taurus, 2005.

(5) Cf. El Mercurio, 22 octubre 1944; El Imparcial, 22 octubre 1944, p. 8.

(6) El Mercurio, 22 diciembre 1944. 
viviendas. Una noticia del 2 de febrero habla de 5 mil niños vagos en Santiago y se refiere a un proyecto de crear un refugio para ellos, impulsado por Polidoro Yáñez, miembro de la comisión de la Dirección de la Protección de la Infancia, dependiente del Ministerio de Salubridad. El artículo, describe las espantosas condiciones de vida de estos menores vagos y el injusto trato que reciben por parte de las autoridades. El autor de la nota del diario se muestra escéptico frente a la creación del refugio, pues cuatro años antes se había propuesto lo mismo, sin resultados (7). De hecho, pocos días después, el 21 de febrero, el mismo diario da cuenta del fracaso de las gestiones de crear un asilo, pues las autoridades, ante la petición, respondieron: "no hay dinero" (8). Estas noticias, directa o indirectamente, debieron llegar al Padre Alberto Hurtado, pues en varios documentos cita la misma cifra de 5 mil niños vagos.

Por otra parte, la inquietud por la falta de vivienda, en especial, para obreros, está bien presente en la prensa, lo que muestra que la preocupación flotaba en el ambiente (9). Así lo muestra, por ejemplo, la buena acogida en el Senado del proyecto de viviendas populares impulsado por particulares (10). También es indicativo que la Semana Social de la Acción Católica, en la sesión del jueves 24 de agosto de 1944, aborda el tema de la solución de las viviendas populares en el país (11).

Pero una cosa es la preocupación por la vagancia infantil y otra bien diferente son los motivos que sustentan esta preocupación. Llama la atención que los niños vagos se ven como un problema solo por los peligros e incomodidades que generan a los santiaguinos y, sobre todo, a los extranjeros. Esta insana preocupación por la imagen de Chile ante los extranjeros queda de manifiesto en un artículo del Ilustrado, llamado Hay negligencia para solucionar el problema de la vagancia infantil, del 21 de febrero de 1944:

"Fuimos espectadores en una oportunidad-relata el periodista-del caso de un señor que salió del principal Hotel de nuestra capital, y a quien se acercaron varios mendigos que jugaban o esperaban en la Plaza Bulnes. Como el mencionado señor no les dio dinero, procedieron a injuriarlo en forma soez: a lo que el aludido contestó con una frase cualquiera, y, lo que es peor, con un marcado acento extranjero" (12).

Según el artículo, lo más grave es la molestia sufrida por el extranjero, mientras está ausente la preocupación por los niños. El inicio del texto se lamenta que las autoridades no hayan cumplido su obligación de "reprimir de una vez por todas la vagancia y la mendicidad infantil”. Y el artículo concluye con la siguiente recomendación:

(7) Cf. El Diario Ilustrado, 2 de febrero de 1944, p. 6.

(8) El Diario Ilustrado, 21 de febrero de 1944, p. 1.

(9) Para una visión de conjunto, cf. Rodrigo Hidalgo, Continuidad y cambio en un siglo de vivienda social en Chile (1892-1998). Reflexiones a partir del caso de la ciudad de Santiago, en Revista de geografía Norte Grande, 26 (1999), p. 69-77 (con bibliografía).

(10) Cf. El Diario Ilustrado, 6 de junio de 1944, p. 3; El Diario Ilustrado, 7 de agosto de 1944, p. 3.

(11) Cf. El Diario Ilustrado, 24 de agosto de 1944, p. 4.

(12) El Diario Ilustrado, 21 de febrero de 1944, p. 1. 
"Finalmente, se nos ha pedido insinuar por medio de estas columnas, a las autoridades correspondientes, que se adopten medidas rápidas y efectivas, que se evite que los niños vagos lleguen a ser delincuentes por el ambiente en que viven, y que se evite a los extranjeros la molestia de verse continuamente asediados por menores limosneros, lo que en ellos lógicamente, produce una desagradable impresión que va en desmedro de nuestro país” (13).

Como se ve, al menos en estos párrafos, la preocupación por los propios niños está totalmente ausente, solo interesa que no sean un peligro o una molestia para los demás, en especial, para los extranjeros (!). No es justo considerar esta nota como representativa del sentir de la sociedad santiaguina de la época, pero el tono del escrito, manifiesta que este modo de abordar el tema, al menos en algunos ambientes, estaba pacíficamente asumido.

Otro antecedente, que muestra la presencia de la preocupación por los sin casa, es una iniciativa de la Acción Católica un par de años antes. Si bien la documentación es muy escasa, por un par de cartas, sabemos que, posiblemente entre 1942 y 1943, funcionó un albergue para recibir indigentes organizado por la Acción Católica. La institución funcionaba solo durante los meses de mayor necesidad. Este albergue tenía por nombre "Hogar de todos" (14). En esta misma línea, otras iniciativas católicas, como el Hogar San Pancracio, buscaban hacer "realidad social los deseos generosos de servir al prójimo” (15).

\section{ANTECEDENTES: TEOLOGÍA DEL CUERPO MÍSTICO DE CRISTO}

A partir del año 1944, en los manuscritos del Padre Hurtado, se encuentran descripciones muy vívidas de los dolores humanos, particularmente de la guerra, de los trabajos duros y de la pobreza, y una fuerte insistencia en que el cristiano debe experimentar los dolores ajenos como si fueran propios. Todo esto relacionado a la teología del Cuerpo Místico:

“Cuando el mundo yacía oprimido por centenares de miles de toneladas de bombas y los campos ensangrentados por millones de cadáveres, después de haber hecho inútiles tentativas diplomáticas, [el Papa Pío XII] escribe a los fieles todos una impresionante Encíclica sobre el Cuerpo Místico de Cristo, para recordarles que son hermanos, que han de amarse como hermanos, ya que son uno en Cristo, hijos del mismo Padre Dios [...]. Al ver los sufrimientos que los agotan, muchas veces el hambre, las enfermedades, la muerte prematura que ronda sus hogares, la comprensión del mensaje de Cristo me dice que no amo bastante, que no soy bastante hermano de todos los que sufren, que sus dolores no llegan bastante al fondo de mi alma, y quisiera, Señor, estar ator-

(13) El Diario Ilustrado, 21 de febrero de 1944, p. 1.

(14) Estos datos se recogen de una carta de los jóvenes de la Acción Católica al Padre Hurtado del 22 de octubre de 1944 y de la carta de Alberto Hurtado a Matías Errázuriz, del 27 de octubre.

(15) El Diario Ilustrado, 5 de mayo de 1944, p. 1. 
mentado por hambre y sed de justicia que me torturara para desear para ellos todo el bien que apetezco para mí” (16).

Llama la atención el carácter concreto de la descripción de los sufrimientos humanos y su estrecha vinculación con la teología del Cuerpo Místico. Esta teología estuvo muy presente en la formación teológica de Alberto Hurtado, particularmente por la lectura de Columba Marmion y Émile Mersch (17), profesor de Lovaina, y recibió un gran impulso con la publicación de la Encíclica Mystici Corporis Christi, en junio de 1943. Sabemos que el curso que dio el Padre Hurtado a la juventud femenina de la Acción Católica, entre abril y mayo de 1944, fue precisamente sobre el Cuerpo Místico ${ }^{18}$. El aviso del diario es significativo, pues afirma que "Junto con mostrar este hermoso Dogma del Cuerpo Místico de Cristo, el R. P. Hurtado nos dará a conocer todas las consecuencias que de él se desprenden para nuestra vida" (19). Efectivamente, la novedad que aporta Alberto Hurtado no es el contenido del dogma, sino sus consecuencias para la vida cristiana. De hecho, años más tarde, afirmará: "Utilísimo sería que esta doctrina [del Cuerpo Místico] fuera estudiada a fondo en todas sus consecuencias y en todas sus aplicaciones" (20). Esta doctrina desplegará nuevas consecuencias, a partir de los dos decisivos encuentros, aludidos más arriba, que San Alberto Hurtado experimentó como encuentros con Cristo mismo.

\section{DOS ENCUENTROS DECISIVOS}

El primero de estos encuentros se produjo en 1944, durante el invierno. La familia Irarrázaval Larraín recogió en su casa a una señora indigente en las más dramáticas condiciones. Inmediatamente, la señora Virginia Larraín llamó al Padre Hurtado que acudió prontamente. "Nunca olvidaré su actitud-escribió la señora Virginia-, que fue la más elocuente de las prédicas”, asimismo, su hija Margot recuerda que "el Padre Hurtado estuvo largo tiempo con la enferma, sujetándole la cabeza con cariño" (21). Le hablaba de Dios como a un niño, la siguió visitando y

(16) El deber de la Caridad, publicado en La búsqueda de Dios. Conferencias, artículos y discursos pastorales del Padre Alberto Hurtado, S. Fernández Eyzaguirre (ed.), Ediciones Universidad Católica de Chile, Santiago 2005, p. 145.

(17) Algunos artículos de É. Mersch influyeron decisivamente en los documentos de Alberto Hurtado, anteriores a la publicación de la Mystici Corporis Christi. Se puede comparar, por ejemplo, el retiro para profesores de la Universidad Católica de 1940 (publicado en Un disparo a la eternidad. Retiros espirituales predicados por el Padre Alberto Hurtado, S. Fernández Eyzaguirre (ed.), Ediciones Universidad Católica de Chile, Santiago 2002, pp. 79-85) con el artículo de Émile Mersch, La vie historique de Jésus et sa vie mystique, NRT LX (1933), pp. 5-20. Cf. Jaime Castellón, Padre Alberto Hurtado S.J. Su espiritualidad, Santiago, 1998, pp. 22-26.

(18) Cf. El Diario Ilustrado, 7 de abril de 1944, p. 2.

(19) El Diario Ilustrado, 12 de abril de 1944, p. 11.

(20) Humanismo social, Santiago 1947, p. 31.

(21) Este encuentro ha sido posible reconstruirlo sobre la base de una carta, de mayo de 1971, de la Señora Virginia Larraín al Padre Álvaro Lavín y del testimonio de su hija, Margot Irarrázaval, recogido durante el 2008 por el Padre Juan Ochagavía. 
decidió bautizarla. La mujer murió, pocos días después en el Hospital Salvador (22). Estos datos iluminan otras alusiones a esta misma situación, contenidas en dos manuscritos de Alberto Hurtado, que reflejan el impacto de este encuentro. En una conferencia a señoritas sobre "La preparación de la mujer para la época de la postguerra”, del 21 de noviembre de 1944, afirma:

"Hay entre nosotros trescientos mil tuberculosos, de los cuales más de veinte mil mueren cada año por esta enfermedad: no hay hospitales donde albergarles, y van a esconder su miseria y su dolor a cuevas inhumanas del [río] Mapocho, debajo de sus puentes, donde agonizan y mueren. El invierno último: la mujercita de la señora Virginia: ¡inanición, hambre, frío!” (23).

Lo mismo se puede afirmar de otro documento, una meditación titulada "Hambre y sed de justicia", predicada posiblemente en un retiro para miembros del Servicio de Cristo Rey, mismo año 1944:

"Tendríamos que vivir algunos meses en un país hambriento, cuando ya no hay nada, absolutamente nada que comer, no porque la panadería esté cerrada, sino porque la región entera carece de comestibles y los famélicos, esqueléticos, van acabando su vida en grupos, esperando cada uno la hora inevitable. Muertos de hambre: la mujercita que recogió la señora Virginia Larraín... El hambre y la sed han perdido su espanto para nosotros” (24).

Llama la atención la vivacidad con que Alberto Hurtado describe los dolores y sufrimientos de la pobreza. Insiste que es necesario "vivir" el hambre para conocerlo. Esta será la tónica de los escritos de estos años.

El segundo encuentro, más conocido, es el con el mendigo, en octubre de 1944. El artículo del diario El Mercurio del 22 de octubre, describe el dolor:

“... de esos pobres hermanos nuestros, hijos del mismo Padre Dios que vagan por las calles sin tener donde cobijarse, si no es debajo de los puentes del [río] Mapocho, o en el hueco de una puerta de calle, como los hemos encontrado

(22) En una carta al Padre Lavín, la señora Virginia Larraín cuenta que su hija acogió a una pobre mujer que estaba siendo reprendida por un carabinero. "Confieso -escribe la señora Larraín-que ignorando lo acaecido, y no compartiendo la nobleza e impetuosidad de mi hija, me desesperé al encontrarme frente a una infeliz, apenas capaz de articular unas cuantas palabras, sucia hasta lo inservible, desgreñada y con un olor a podredumbre imposible de aguantar... Dominé mi repugnancia y comprendí que, como cristiana, no podía anular con mis actos las enseñanzas de Cristo y que no me quedaba sino, recibir este regalo de Dios... Desesperada llamé de inmediato al Padre Hurtado para que me solucionara esta situación, el cual llegó a los pocos minutos". Luego afirma que el Padre Hurtado, sentado sobre dos ladrillos junto la cabecera de la cama en que yacía esta pobre señora, pasaba largo rato con el brazo bajo la almohada, para estar más cerca de esta pobre mujer. Le hablaba de Dios y de su misericordia infinita como a un niño. El Padre se mantenía alegre, sonriente, fraternal y afectuoso. Decidió bautizarla y la siguió visitando hasta su muerte, pocos días después (de tuberculosis pulmonar e intestinal, y de sífilis). "Pocos días más tarde, mi hijo menor, que estaba en San Ignacio, contó que en el sermón, el Padre Hurtado, se había referido a este caso".

(23) Charitas Christi urget me, 1944, APH s40y05 (APH = Archivo Padre Hurtado, sobre y número del documento).

(24) Bienaventurados los que tienen hambre y sed de justicia, en Un disparo a la eternidad, p. 257. 
tantas mañanas de invierno tiritando de frío, medio muertos por el hielo de la noche. Recuerdo una pobre mujer recogida en una casa caritativa cuando caía víctima de inanición, a la que fui a asistir como sacerdote y murió al poco tiempo de hambre y del dolor de sus largas privaciones... Recuerdo hace pocos días, uno de esos lluviosos de primavera, un pobre hombre con una amigdalitis aguda, tiritando, en mangas de camisa, que no tenía donde guarecerse” (25).

La "pobre mujer recogida en una casa caritativa" se refiere, naturalmente, a la mujer que acogió la señora Virginia Larraín. El encuentro con el pobre hombre con amigdalitis es el que se produce durante los días que predicaba un retiro a señoras en el Apostolado Popular, y es el antecedente inmediato de la inspiración de fundar el Hogar de Cristo. Al estudiar el retiro, se presentarán los datos relativos al encuentro con el mendigo.

\section{EL RETIRO A SEÑORAS EN LA CASA DEL APOSTOLADO POPULAR}

Un artículo que relata las circunstancias de la génesis del Hogar de Cristo, escrito por el Padre Hurtado en 1948, describe estos mismos hechos entregando interesantes detalles. El documento afirma que durante un retiro, "el tema de su predicación era un llamado a la generosidad cristiana”. Durante la charla, describe la dramática situación de la que ha sido testigo: "Cristo vaga por nuestras calles en la persona de tantos pobres dolientes, enfermos, desalojados de su mísera habitación” (26), y luego recuerda el carácter inesperado del impulso de fundar una obra:

“PProyecto de alguna obra nueva envolvían estas palabras? Ninguno, ciertamente. Pero, ¿no prometió acaso el mismo Cristo que cuando Él quiera servirse de los hombres para realizar una obra, pondría en sus labios lo que él quería obtener? Y así sucedió palpablemente en este caso. Al terminar la predicación, dos de los oyentes se acercan al predicador y le ofrecen, una, el terreno para iniciar un Hogar para Cristo pobre, y otra, una suma de dinero con qué iniciar los trabajos [...] y así, en diciembre del mismo año [1944], un par de meses después, se colocaba la primera piedra del primer Hogar. Y esa primera piedra estaba cargada de bendiciones" (27).

(25) El Mercurio, 22 diciembre 1944.

(26) Propaganda del Hogar de Cristo, 1948, APH s71y002. Vale la pena ofrecer el primer párrafo del texto, en que habla en tercera persona: "En octubre de 1944 predicaba ejercicios un sacerdote. El tema de su predicación era un llamado a la generosidad cristiana... Tanto dolor que remediar: Cristo vaga por nuestras calles en la persona de tantos pobres dolientes, enfermos, desalojados de su mísera habitación. Cristo, acurrucado bajo los puentes en la persona de tantos niños que no tienen a quien llamar padre, que carecen ha muchos años del beso de madre sobre su frente. Bajo los mesones de las pérgolas en que venden flores, en medio de las hojas secas que caen de los árboles, allí tienen que acurrucarse tantos pobres en los cuales vive Jesús. ¡Cristo no tiene hogar! ¿No queremos dárselo nosotros los que tenemos la dicha de tener hogar confortable, comida abundante, medios para educar y asegurar el porvenir de los hijos? "Lo que hiciereis al menor de los pequeñuelos, a Mí lo hacéis", ha dicho Jesús". 
Un pequeño aviso de El Diario Ilustrado permite precisar que está situación corresponde al retiro predicado a señoras, en la casa del Apostolado Popular (calle Lord Cochrane 104), del 16 al 21 de octubre (28). A partir de los datos de otros años se deduce que pudieron haber participado unas 200 señoras y señoritas en este retiro (29).

A partir del esquema del mismo retiro, que ha sido identificado entre los manuscritos que se conservan en el Archivo (30), se puede conocer al menos los títulos de las meditaciones del retiro. Primer día: 1 . Hambre y sed; 2 . Grandeza de la vida; 3. Hijos de Dios; 4. Cielo e infierno. Segundo día: 1. La mujer vieja y la mujer nueva; 2. Abnegación; 3. Examen de conciencia y confesión. Tercer día: 1. El conocimiento de Cristo; 2. Nacimiento; 3. Pastores; 4. Magos. Cuarto día, el 19 de octubre: 1. Generosidad y tres clases humildad; 2. Apóstoles (multiplicación panes); 3. Vocación y vocaciones; 4. María modelo de generosidad (mansedumbre, Charles). El último día: 1. Vida interior; 2. Oración; 3. Dos últimas palabras Señor en la cruz; 4. Emaús.

Según las palabras de Alberto Hurtado, la inspiración de fundar el Hogar de Cristo fue el día del retiro en que predicaba sobre la generosidad cristiana, y, más precisamente, "al terminar la predicación", lo que indica el 19 de octubre en la tarde. De hecho, un archivador con recortes de prensa recogidos por Rebeca Jullien de Franke, en su segunda página, afirma: "Se lanzó la idea [del Hogar de Cristo] el 19 de octubre de 1944" (31). Una vez establecido este dato, se deduce la fecha del encuentro con el mendigo. Es iluminador el testimonio de la misma Rebeca Jullien:

"Recuerdo que yo asistía a un retiro en la Casa del Apostolado Popular, en una de sus predicaciones el Padre Hurtado hizo ver la terrible situación de los pobres que no tenían dónde vivir y contó que la noche anterior se había encontrado con un mendigo, a media noche, en las puertas de San Ignacio, atacado de una fuerte amigdalitis y al que tuvo que darle dinero para que fuera a alojarse al hogar que mantenía el Ejército de Salvación” (32).

Otra declaración del Proceso Cognicional intenta reproducir las palabras del Padre Hurtado durante el retiro: "Anoche vi a Cristo tiritar de frío; esto no puede seguir, tenemos que hacer algo por Cristo que sufre; los únicos cristianos que hacen algo por esta necesidad son los hermanos protestantes del Ejército de Salvación; los católicos tenemos que hacer algo para albergar a Cristo sin hogar” (33). Según otro testimonio, cuando terminó de hablar de la terrible situación de los pobres, se arrodilló ante el Santísimo Sacramento como era habitual, pero

(28) Cf. El Diario Ilustrado, 11 octubre 1944, p. 8

(29) Según las memorias anuales del Apostolado Popular, en el retiro de octubre de 1938 participaron unas 150 señoras y señoritas, en 1940 fueron 170 ejercitantes, en 1941 se habla de 200 personas, en 1946 se señala la participación de 130 señoras y en 1950 participaron 280 señoras y señoritas.

(30) Señoras, 1944, APH s39y04a.

(31) Cf. Libro de recuerdos del Hogar de Cristo, de Rebeca Jullien de Franke (APH).

(32) Proceso Cognitional, Sesión 74.

(33) Proceso Cognicional, Sesión 26. El testigo, P. Raimundo Barros, afirma que esto lo escuchó "de personas que asistieron a ese retiro". 
luego se volvió a levantar y, como “transfigurado” (34), invitó a las señoras a realizar una obra (35).

La combinación de estos datos permite establecer con precisión la fecha, la hora y el lugar del encuentro con el mendigo: el 18 de octubre, a medianoche, en las puertas de la Iglesia de San Ignacio.

\section{CONTENIDO DE LA PREDICACIÓN DEL 19 DE OCTUBRE}

Del cuarto día del retiro, se conserva el desarrollo de la segunda y cuarta meditación. La segunda se llama “Apostolado (multiplicación de los panes)”. La meditación insiste, por una parte, en la insuficiencia de nuestros recursos: cinco panes duros y dos pescados, machucados y descompuestos, para alimentar a 5.000 hombres; y, por otra parte, en la enorme fecundidad que estos pobres elementos pueden tener cuando son ofrecidos con generosidad en las manos de Cristo:

"Yo... como esos peces, (menos que esos panes) machucados, quizás descompuestos; pero en manos de Cristo: mi acción puede tener alcance divino” (36).

La consideración de la desproporción entre la pobreza de los recursos y la magnitud de las necesidades, y la meditación de la también desproporcionada fecundidad de la acción divina cuando cuenta con la colaboración humana preparan el ambiente de la fundación del Hogar de Cristo.

También se conserva el texto de la cuarta meditación, es decir, la última del día. Lleva por título María modelo de generosidad. Este documento insiste en que María es quien mejor imita a Cristo:

"Cristo, nuestro modelo, y quien mejor lo imita, María en su bondad, porque hizo de su vida un servicio. A los cuatro años a servir; 'ancilla', visitación, sirve a donde Dios la guíe: en Egipto, Nazareth, Caná, limosnas... de lejos. Madre [de la] Iglesia, 'la que sirve', sin tregua ni descanso. Y en su vida bondad, mansedumbre. Esa, la vida de la mujer cristiana. Servir en bondad” (37).

María es la que mejor imita a Cristo, "porque hizo de su vida un servicio". La vinculación entre la imitación de Cristo y el servicio a los demás, que tiene a María como modelo, es otro elemento que está presente en el momento de la inspiración de la fundación del Hogar de Cristo.

(34) Marta Holley, presente en el mismo retiro, declaró: "el Padre estaba transfigurado", Proceso Cognicional, Sesión 30.

(35) "Terminó la predicación, se hincó ante el Santísimo, como era su costumbre, y nuevamente se volvió hacia nosotras y como iluminado dijo que los católicos debíamos hacer algo y que teníamos que hacer algo. De inmediato, por iniciativa de las Señoras, se hizo una colecta. Algunas se desprendieron de sus joyas, otras dieron dinero y una dio un terreno donde podría edificarse el Hogar”, Mercedes Peña de Ruiz Tagle, Proceso Cognicional, Sesión 84.

(36) Multiplicación de los panes, en Un disparo a la eternidad, p. 137.

(37) El modelo de la mujer generosa: María, [1944], APH s40y01. Esta meditación depende de un retiro del Padre Pierre Charles. 
El breve artículo de 1948 asegura que, cuando le vino la idea de fundar el Hogar de Cristo, hablaba de la generosidad y que se le acercaron dos señoras con las primeras donaciones "al terminar la predicación”. Esto apuntaría a la última meditación, es decir, María modelo de generosidad. Dato confirmado por una prédica de San Alberto Hurtado, del 4 de diciembre de 1946, en la Iglesia de San Francisco, durante el Mes de María, es decir, dos años después de la fundación del Hogar:

"Con vuestra ayuda se fundó [el Hogar de Cristo]. Hace 2 años se dirigió invitación desde aquí para primera piedra. [Hoy] 4 casas: niños... adolescentes, adultos: Hay centenares que rechazar cada día [por falta de espacio]. Si quisierais, en este 8 de diciembre, haceros cargo de la educación de un vago, apadrinar; tomar a vuestro cargo los gastos para alojar a un pobre que sufre, iy es el predilecto de Cristo! En una inspiración de fe, bajo la Virgen, nació [esta] obra, hoy os la recomiendo: llenadla, apadrinad un niño, dadnos los medios necesarios para recibir un pobre más, para que Cristo tenga cama y María la Madre de los pobres os lo agradecerá de corazón” (38).

Este texto indica que la invitación para poner la primera piedra del Hogar de Cristo se hizo durante una prédica del Mes de María de 1944, en la Iglesia de San Francisco, y que esta obra, según las propias palabras del Padre Hurtado, nació "en una inspiración de fe, bajo la Virgen", lo que confirma que la inspiración de fundar el Hogar estuvo vinculada con la meditación de María como modelo de generosidad $y$ de servicio. De este modo, se fortalece la vinculación entre "María, la Madre de los pobres” y la inspiración y el desarrollo del Hogar de Cristo (39).

\section{¿CÓMO EXPERIMENTÓ EL PADRE HURTADO ESTOS SUCESOS?}

Los datos aportados por las fuentes permiten percibir la vehemencia con que la idea de fundar un hogar para indigentes se apoderó de él. En el artículo de 1948, citado más arriba, el propio Padre Hurtado asegura que su predicación no envolvía proyecto alguno y que las palabras que invitaban a crear un hogar para Cristo pobre fueron "palpablemente" puestas en sus labios por el mismo Cristo, de acuerdo con la promesa evangélica (40). En el artículo del 22 de octubre de 1944, afirma: la idea de formar un hogar para los pobres "me ha golpeado más fuerte, en forma imprevista” (41). Asimismo, las Actas del Consejo Nacional de la Acción Católica del 20 de octubre de 1944, es decir, pocas horas después de la inspiración de fundar el Hogar, registran que, en esa reunión, el Padre Hurtado dijo que lo había “asaltado” la idea

(38) Los Pobres, [1944], APH s57y13a. Son notas personales, con una redacción 'telegráfica'.

(39) Además, el primer boletín del Hogar de Cristo, parte con una reflexión mariana: "Mira hijito, hace casi dos mil años la Virgen María se puso en camino a Belén. Hacía mucho frío... ”, Las más felices Navidades, 1946, APH s10y08.

(40) El Hogar de Cristo, [1948], APH s71y002. Cf. Mt 10,20.

(41) El Mercurio, 22 diciembre 1944. El P. Fernando Karadima confirma este dato: "Por lo que el Siervo de Dios me refirió, sé que esta idea de fundar el Hogar de Cristo nació en él, en una forma inesperada”, Proceso Cognicional, Sesión 36. 
de fundar un "Albergue católico para indigentes", idea que "se le ocurrió" durante un retiro (42). Y, finalmente, en una prédica del mes de María de 1946 recordó que el Hogar de Cristo nació “en una inspiración de fe, bajo la Virgen”. De este modo, después del encuentro con el mendigo, movido por las palabras que experimentó "palpablemente" como puestas por Cristo en sus propios labios, Alberto Hurtado se sintió fuertemente "golpeado... en forma imprevista", e incluso "asaltado" por la idea de fundar un hogar para los pobres. Idea que él mismo percibió como "una inspiración de fe, bajo la Virgen”. Es evidente, entonces, que San Alberto experimentó este impulso no como una idea propia, sino como una iniciativa de Dios.

\section{CONFIRMACIÓN ECLESIAL DE LA INSPIRACIÓN DEL PADRE HURTADO}

La primera reacción eclesial que recibió el Padre Hurtado fue la generosidad de las señoras que participaban en el retiro, que ofrecieron algunas joyas, una suma de dinero y un terreno, elementos insuficientes para una obra tan grande:

“Apenas propuesta la idea, varias personas la acogieron con gran entusiasmo: También ellas habían sentido la misma inquietud: solo faltaba hacerla cristalizar. Algunas joyas modestas, pero llenas de valor espiritual, algunas limosnas se erogaron inmediatamente y algunas promesas se han insinuado de una ayuda que se hará efectiva" (43).

No es difícil asociar esta escena con la del niño ofreciendo a Jesús cinco panes y dos peces, comentada aquel mismo día, en la meditación de la multiplicación de los panes (cf. Jn 6,1-15). Inmediatamente a continuación, el Padre Hurtado sintió la necesidad de confrontar su proyecto con la voz de la Iglesia y "se apresuró" a hablar con el Cardenal Caro. El artículo del 22 de octubre de 1944 y, por lo tanto, que debió ser escrito el 21, afirma:

"Ayer [20 de octubre] regresaba a Santiago el Excmo. Señor Arzobispo Dr. José María Caro y me apresuré a proponerle el proyecto y solicitar su bendición que la impartió amplia, alentadora, cargada de la promesa de sus tradiciones" (44).

Si bien casi no hay documentos que lo respalde, ciertamente debemos suponer que antes de hablar con el Cardenal Arzobispo de Santiago, Alberto Hurtado

(42) El texto del Acta dice: "Albergue católico para indigentes. El Padre Hurtado expuso que lo había asaltado la idea de organizar un albergue católico por encontrarlo indispensable. Que esta idea tuvo muy buena acogida en un retiro para señoras durante el cual de se ocurrió y cree que podría realizarse. Pide poder hablar sobre esto en el cuarto de hora de Radio Mercurio, transmisión 'Luz'. Se le rogó ponerse de acuerdo con la Sub-directora del Secretariado de Prensa y Propaganda”. Acta del 20 de octubre de 1944, p. 2. Más allá de su deficiente redacción, el documento es interesantísimo, puesto que se trata de un testimonio contemporáneo, que refleja cómo una tercera persona registró el estado del Padre Hurtado después de estos acontecimientos.

(43) El Mercurio, 22 diciembre 1944.

(44) El Mercurio, 22 diciembre 1944. 
debió haber consultado su proyecto con su superior religioso, el Padre Pedro Alvarado $(45)$.

Impresiona la rapidez de los acontecimientos: el encuentro con el mendigo fue el 18 de octubre, a medianoche, la inspiración de fundar el Hogar fue el 19, en la tarde, el 20 de octubre recibió la bendición del Cardenal para su nuevo proyecto y el mismo día 20, propone la idea de un hogar para indigentes en la reunión del Consejo Nacional de la Acción Católica.

A la inicial colaboración de las señoras, se suma la oferta del propio trabajo por parte de un grupo de jóvenes: el mismo 22 de octubre, día de la publicación del artículo, recibe una carta en que un grupo de jóvenes que, habiéndose reunido en la Procesión de la Virgen del Carmen, reaccionan de inmediato a la lectura del artículo y ofrecen una modesta suma de dinero y la promesa "de colaborar con nuestro trabajo personal a la construcción del nuevo Hogar” (46), la carta está firmada por varios jóvenes de la Acción Católica y fue publicada pocos días después en El Mercurio. Asimismo, los jóvenes de la Guardia de Honor del Santísimo Sacramento, el 25 de octubre, le escriben una carta, acudiendo al llamado de preocuparse por los más desamparados, los que no tienen ni techo, y en ella se ofrecen a tomar a su cargo "las labores que sean necesarias para hacer realidad esta trascendental obra social" (47). También reacciona la Juventud Católica Femenina que, el 28 de octubre, publica en El Diario Ilustrado una carta adhiriendo a la iniciativa del Padre Hurtado (48).

La amplia y alentadora bendición del Cardenal y la generosa e inmediata reacción de las señoras, de los jóvenes y de las jóvenes católicas, "apenas propuesta la idea”, es vista por Alberto Hurtado como una confirmación ulterior de la autenticidad de la inspiración de fundar el Hogar (49). Contando con esta colaboración, el jueves 21 de diciembre del mismo año, se puso la primera piedra del Hogar, "y esa primera piedra estaba cargada de bendiciones".

\section{UN MALENTENDIDO Y EL PROPÓSITO INICIAL DEL HOGAR}

El citado artículo del 22 de octubre de 1944, asegura que solo el Ejército de Salvación, protestante, cuenta con un hogar para los sin casa. Esta afirmación pro-

(45) Según la declaración del Padre Raúl Montes, la fundación del Hogar de Cristo “encontró amplia acogida del Arzobispo de Santiago y en el Provincial de los Jesuitas”, Proceso Cognicional, Sesión 47; Elsa Maffei, por su parte, declara, a propósito del Hogar: "me consta que pidió consejo a su superior y al Señor Arzobispo. Nunca él daba un paso sin consultar con los superiores", Proceso Cognicional, Sesión 30; Ramón Venegas dice: "Siempre el Siervo de Dios pedía consejo y autorizaciones a sus Superiores”, Proceso Cognicional, Sesión 23.

(46) Carta recibida, 22 diciembre 1944. Publicada en El Mercurio, el 5 de noviembre de 1944.

(47) El Diario Ilustrado, 26 de octubre de 1944, p. 4.

(48) Cf. El Diario Ilustrado, 28 de octubre de 1944, p. 3.

(49) En un artículo enumera quienes han respondido con prontitud: "Las Academias de Arquitectos y de Ingenieros Católicos [...]. Los jóvenes católicos, especialmente la Guardia de Honor, liceanos católicos y otros grupos [...]. Los jóvenes del Instituto de Educación Familiar [...]. Un grupo de socias de la juventud Católica Femenina [...]. Al llamado por la prensa han respondido numerosos bienhechores [...], otros han enviado limosnas, siendo muy numerosas las pequeñas limosnas de los pobres que atraen especiales condiciones del cielo”, El Diario Ilustrado, 17 de diciembre de 1944 , p. 6. 
vocó malestar entre algunos católicos que ya sostenían alguna obra de beneficencia semejante. Don Matías Errázuriz escribió un artículo en el diario El Imparcial, el jueves 26 de octubre de 1944, que recuerda que los padres de Don Orione tienen dos casas para acoger a los indigentes, y que, por tanto, la Iglesia Católica ya posee la obra que el Padre Hurtado anhela (50). Pocos días después, el 31 de octubre, apareció un artículo en El Diario Ilustrado, firmado por Julia Vial de Guzmán, afirmando que "en silencio, sin ostentación, filántropos de nuestra sociedad se han anticipado, al llamado de urgencia, del Reverendo P. Hurtado" (51), aludiendo al "Asilo Patricio Ossa Vicuña”, que funcionaba en Cerrillos. Esta situación motivó una carta personal en que Alberto Hurtado le explicó a Matías Errázuriz la diferencia entre su proyecto y las obras existentes (52). La carta explicita la intención específica del nuevo hogar:

"Yo desearía construir un hogar para los pobres, adultos y niños, que transitoriamente están sin hogar, sea porque las familias han sido lanzadas a la calle como ocurre tantas veces, sea porque son provincianos que llegan y no tienen dónde cobijarse, o porque por su imprevisión están en la miseria. No sería un hogar permanente para ellos, sino la obra sería transitoria: el dar posada al peregrino de que nos habla Nuestro Señor. Junto con el techo se les daría alimento a ellos, y si fuera posible también a otros indigentes que lo necesitan" (53).

El texto es claro: la novedad del proyecto sería dar albergue transitorio, no permanente (como otras obras católicas). Este malentendido debió ayudar al Padre Hurtado a explicitar la finalidad específica de la nueva obra católica, que en el artículo del 22 de octubre permanecía genérica (54). El 28 de octubre, don Matías Errázuriz escribe a Alberto Hurtado dando por superado el malentendido.

El 17 de diciembre, el Padre Hurtado publica un nuevo artículo con un título más modesto: Un hogar más para los que no tienen techo (55), en que, junto con invitar a la primera piedra del Hogar de Cristo, destaca, después de este incidente, las "muchas otras instituciones que tiene la Iglesia para socorrer a los pobres"

(50) Cf. El Imparcial, 26 de octubre de 1944, p. 4.

(51) El Diario Ilustrado, 31 de octubre de 1944, p. 3.

(52) El Padre Hurtado destaca la diferencia de su proyecto con las obras existentes: "Me he informado cuidadosamente de la obra que realizan los Padres de Don Orione y creo poderle afirmar que mi proyecto está encaminado en otro sentido de lo que ellos han realizado hasta ahora. Según mis informaciones tienen los Padres dos asilos uno en Lo Valdivieso para unas 80 niñitas, habiendo además algunas veces recibido algunas ancianas; y otro para niños en Cerrillos, con igual número aproximadamente. Ambas obras son espléndidas, muy necesarias y Dios quiera que puedan seguir prosperando y aumentando sus posibilidades de recepción”, Carta a Matías Errázuriz, 1944, APH s64y20.

(53) La carta es del 27 de octubre de 1944, APH s64 y 20.

(54) El artículo del 22 de octubre es muy genérico y refleja intenciones bastante más amplias que la carta del 27: "dar posada al mendigo, darle alimento, darle educación, si fuese posible iniciar a algunos en un trabajo que los haga escapar de su horrible miseria”, El Mercurio, 22 diciembre 1944.

(55) Cf. El Diario Ilustrado, 17 de diciembre 1944, p. 11. El título es más modesto que el del artículo de octubre: Hogar para los que no tienen techo. 
(56). Esto muestra el carácter conciliador y abierto a las correcciones de Alberto Hurtado.

\section{EL NOMBRE “HOGAR DE CRISTO”}

En la carta del 27 de octubre, el Padre Hurtado todavía no habla de Hogar de Cristo, sino simplemente de Hogar para indigentes, como lo había hecho en el consejo de la Acción Católica. Asimismo, la carta de la Juventud Católica Femenina habla de un hogar para los desvalidos (57), y el breve artículo de Ramón Venegas, del 5 de noviembre de 1944, habla genéricamente de "la institución que propicia el Padre Alberto Hurtado Cruchaga” (58). Al parecer, aún no se había aclarado el nombre de la institución.

La primera utilización formal al nombre "Hogar de Cristo" aparece el 17 de diciembre, en el artículo escrito por el Padre Hurtado para invitar a la bendición de su primera piedra. Es significativo recordar que la obra sostenida por la Acción Católica entre 1942 y 1943 se llamaba "Hogar de todos", y la nueva obra tiene un nombre más audaz: "Hogar de Cristo", pues, este último nombre asocia a los más pobres, a los que no tienen techo, los que muchas veces están envueltos en los más variados males, con Cristo mismo. Detrás de esta diferencia de nombre, se encierra un difícil problema eclesiológico. Se trata de la pregunta acerca de quiénes pertenecen al Cuerpo Místico de Cristo, ¿solo los bautizados o todos los hombres? La afirmación "el pobre es Cristo", implícita en el nombre del Hogar, incluye a todos los hombres en el Cuerpo Místico. Para afirmar esto, San Alberto sigue de cerca el libro Le Christ vie de l'ame, cap. XI, de Columba Marmion, pero va más allá, pues llega a afirmar: "basta ser hombre para poder ser miembro del Cuerpo de Místico de Cristo, esto es para poder ser Cristo" (59).

\section{PROYECCIÓN Y NUEVA ORIENTACIÓN EN SU TRABAJO SOCIAL}

Rebasando los límites fijados para esta investigación, vale la pena señalar el cambio de énfasis que se produce en el ministerio sacerdotal de San Alberto a partir de los acontecimientos estudiados. El inicio del Hogar de Cristo precede por pocos

(56) Cf. El Diario Ilustrado, 17 de diciembre 1944, p. 11. "Los Pequeños Cottolengos realizan una hermosa labor albergando a niños desamparados, y esperan poder ampliar más sus servicios, aun para adultos, las Hermanitas de los Pobres amparan a los ancianos que han ido quedando solos en la vida al perder a sus seres queridos: los Talleres de San Vicente y la Escuela Agrícola dan educación gratuita a los niños y los capacitan para adquirir un oficio; las Conferencias de San Vicente tienden la mano a miles de familias que no pueden hacer frente a la vida con sus escasos recursos... Estas y muchas otras instituciones tiene la Iglesia para socorrer a los pobres".

(57) Cf. El Diario Ilustrado, 28 de octubre de 1944, p. 3.

(58) El Mercurio, 5 de noviembre de 1944.

(59) Humanismo Social, p. 30. La comparación precisa entre el texto de Marmion y los del Padre Hurtado permiten observar que San Alberto insiste más en la universalidad de la pertenencia a Cristo, y pone un énfasis particular en el carácter concreto de la pobreza. 
meses su dolorosa renuncia a su cargo de Asesor Nacional de la rama de jóvenes varones de la Acción Católica, cargo que había consumido gran parte de sus energías desde 1941.

En esta nueva situación, marcada por el encuentro con Cristo pobre, la fundación del Hogar y la renuncia a la Acción Católica, se retira de Santiago por un par de meses y comienza a redactar un libro que llevaría el título Vida social y deberes sociales (60). Pocos meses después, Mons. O'Hara le otorga una beca para realizar estudios sociales en la Universidad Católica de Washington. En ese período, que finalmente se redujo a un semestre (de septiembre de 1945 a marzo de 1946), entró en contacto con obras sociales tanto en EE.UU. como en Canadá y comenzó el estudio sistemático de los textos del magisterio social de la Iglesia, estudio que conducirá a la publicación, en 1948, del libro El orden social cristiano en los documentos de la jerarquía católica, que recoge en dos volúmenes una presentación sistemática original de los documentos sociales de la jerarquía católica. Posteriormente, se consolidará su formación social, sobre todo en su viaje a Europa, fundará la ASICh y la revista Mensaje, y emprenderá con más fuerza su labor de formación sindical.

A la luz de este brevísimo recorrido destacamos un par de cosas. Primero, el mismo hecho de emprender la redacción de un libro e iniciar un período prolongado de estudios sociales, justo después de la experiencia del mendigo, revela la importancia que el Padre Hurtado atribuye a la actividad intelectual para fundamentar una acción bien orientada. En segundo lugar, se aprecia cómo el encuentro existencial con Cristo pobre y su natural impulso a resolver los problemas inmediatos de las personas concretas llevan, a San Alberto, a comprobar la insuficiencia de la preocupación individual y a dedicarle tiempo al estudio y a la reflexión intelectual de los problemas sociales que generan la pobreza. Esta observación es importante porque nos muestra que la preocupación individual y la preocupación estructural, en la mente del Padre Hurtado, no se oponen, sino que una alimenta a la otra.

\section{CONCLUSIÓN}

Los datos ofrecidos por las fuentes se revelan generosos para reconstruir la vida de Alberto Hurtado. El trabajo de ordenamiento, recopilación y digitalización de fuentes primarias ofrece a los investigadores abundante material para la elaboración de muchos nuevos trabajos sobre uno de los personajes históricos más relevantes para la historia de Chile y la historia de la Iglesia del siglo XX.

Estos datos permiten profundizar el contexto de la fundación del Hogar de Cristo: La preocupación por el problema habitacional, que flotaba en la sociedad chilena; la teología del Cuerpo Místico; el encuentro con la pobre mujer recogida

(60) Este libro no llegó a publicarse; este proyecto posiblemente derivó en Humanismo Social, que lleva como subtítulo "Ensayo de pedagogía social”. La fecha se deduce de una carta a José Arellano, del 24 de enero de 1945, en que afirma: "Estoy estudiando J.O.C., preparando unas conferencias y un libro sobre nuestro deber social, educación social, vida social”, Cartas e informes, p. 203. Se trata del manuscrito Vida social y deberes sociales, [1945], APH s24y01a. 
por la señora Larraín; el encuentro con el mendigo, la noche del 18 de octubre de 1944; la predicación de la generosidad y de María como modelo de generosidad; la inmediata y positiva reacción de la señoras, y luego de los jóvenes, al llamado del Padre Hurtado y la alentadora bendición de la Iglesia, por medio del Cardenal Caro, son los elementos que condicionan el inicio del Hogar de Cristo. Lo que el Padre Hurtado había predicado tantas veces, adquirió -también para él mismo- un significado nuevo e inesperado a partir de estos dos encuentros en que "constata" la indigencia de los pobres y la presencia de Cristo en ellos (61). Por otra parte, llama mucho la atención la rapidez de los acontecimientos, que se sustenta en la vehemencia con que la idea de fundar un hogar para indigentes se apoderó del Padre Hurtado.

A partir de estos acontecimientos, se ve acentuado en la predicación de San Alberto el carácter concreto de la pobreza y de la presencia de Cristo en los pobres. Un ciclo de conferencias organizadas por la Archicofradía de las Madres Cristianas, para señoritas, en noviembre de 1944, está marcado por esta insistencia. En ellas llama a Cristo "el divino Mendigo" que, mal comido y despreciado, duerme bajo los puentes, en las calles (62), y se pregunta: “¿Podemos estar tranquilos cuando, en día de lluvia, junto a calefacción, mientras Cristo duerme en las calles?” (63); en una carta afirma: "Aún quedan muchos niños debajo de los puentes y tirito al pensar cómo tiritan ellos” (64). Estas descripciones expresan una percepción muy existencial de los sufrimientos. Esta inmediata experiencia de Cristo en el pobre lo lleva a colaborar en el desarrollo de una sociedad estructurada de acuerdo al Evangelio. Aquí resplandece, una vez más, la unidad entre espiritualidad, caridad individual y preocupación por la estructura social.

San Alberto Hurtado, desde joven, conoció la pobreza (65); pero en estos textos se percibe algo distinto: muestran que, de un modo nuevo, experimenta "en lo vivo" el dolor ajeno como propio (66). No sin motivo, llama a colaborar en la fundación del Hogar de Cristo precisamente "a todos los que sienten en lo vivo el dolor de nuestros hermanos" (67).

(61) Una carta del 27 de octubre de 1944, que afirma que la idea de fundar el Hogar de Cristo le vino, al Padre Hurtado, al "poder constatar casos de indigencia extrema de gente que no tenía dónde dormir ni qué comer y no tener dónde enviarlos”, Carta a Matías Errázuriz, 1944, APH s64y20.

(62) Cf. Charitas Christi urget me, 1944, APH s40y05.

(63) Nuestros deberes sociales, [1944], APH s24y02.

(64) Carta a Anita y María [1949], APH s70y028.

(65) Desde su juventud colaboró en los patronatos y en las Conferencias de San Vicente; la elaboración de sus tesis de Derecho y su posterior ministerio sacerdotal, atendiendo a la Población Buzeta, lo llevaron a tener un contacto directo con los pobres.

(66) Así lo expresó el Santo Padre Benedicto XVI, en la audiencia posterior a la canonización de Alberto Hurtado, en octubre de 2005: "A la luz de la verdad del Cuerpo místico, experimentó el dolor ajeno como propio y esto lo impulsó a una mayor dedicación a los pobres”.

(67) El Diario Ilustrado, 17 de diciembre de 1944, p. 6. 


\title{
RESUMEN
}

El artículo busca recoger y relacionar los datos contenidos en las fuentes primarias que permiten describir con precisión las circunstancias específicas de la fundación del Hogar de Cristo. Las fuentes principales utilizadas para este propósito son los manuscritos de San Alberto Hurtado, la prensa contemporánea y otros testimonios. La presentación conjunta y razonada de estos datos arroja una visión coherente y unitaria que ofrece detalles del contexto de la fundación del Hogar de Cristo al establecer cuáles fueron los factores sociales, teológicos, biográficos y espirituales que dieron como resultado una de las obras emblemáticas del Padre Hurtado.

Palabras clave: San Alberto Hurtado, Hogar de Cristo, catolicismo social, vagancia infantil.

\begin{abstract}
This article seeks to gather together and relate the data contained in primary sources that allow the author to describe with precision the specific circumstances surrounding the founding of the Hogar de Cristo. The principal sources used for this end are St. Alberto Hurtado's manuscripts, the contemporary press and other witnesses. The integrative and reasoned presentation of these data creates a coherent and unifying vision which offers details from the context of the founding of the Hogar de Cristo, upon determining what social, theological, biographical and spiritual factors were involved in the end result of one of the emblematic works of Father Hurtado.
\end{abstract}

Key words: St. Alberto Hurtado, Hogar de Cristo, Social Catholicism, Homeless. 